\title{
Comparative Study of working Memory of Visually Impaired Students and Sighted Students
}

\author{
Mrs. Shivi Pathak, Shubham Sharma, Akshyata Ray
}

Department of Psychology, Doon University, Dehradun, India

\begin{abstract}
Memory refers to the system that are assumed to be necessary in order to keep things in mind while performing complex task such as reasoning, comprehension and learning. "We use our eyes to see but it's the brain that translates the information to make an image." When we discussed about visually impaired student there is evidence that they may strengthen their memory skills to compensate for absence of vision. Blind people must rely more than sighted people on auditory input in order to acquire information about the world. The present study was designed to test the hypothesis that blind people have better working memory than sighted individuals for auditory verbal material.
\end{abstract}

Keywords - Working Memory, Visually Impaired Student, Sighted Student, Congenitally Blind.

\section{INTRODUCTION}

Working Memory has been described as an active system for holding and manipulating information over brief periods of time during ongoing cognitive activities. The Working Memory tasks in our study were chosen using the same requirements as Swanson and Luxenberg (2009)[1] used. In all cases, the participants had to remember increasingly more complex information (e.g. increasingly longer lists of numbers, tasks containing both a memory and processing element) in Working Memory and had to retrieve information by answering questions about this stored information. The number of correctly remembered items is a direct measure of WM span during the processing of other information (see also Daneman \& Carpenter, 1980)[2].

According to the multicomponent model of Working Memory developed by Baddeley and Hitch (1974) and Baddeley(1986, 2003a, 2003b)[3][4][5][6], Working Memory can be divided into three subsystems: the phonological loop that allows for the temporary storage of verbal and acoustic information, the visuospatial sketchpad that allows for the storage of visual-spatial information for a short period, and the central executive system that is attention driven with limited control in direct contact with the phonological loop and visuospatial sketchpad and also responsible for coordinating activity.
The touch, memory, and attention skills of blind people have been found to compensate for the absence of vision (Cattaneo \& Vecchi, 2011; Warren, 1978).

Visually impaired students are not more sensitive than sighted students in terms of their ability to discriminate using hearing, taste, touch, and smell. Instead, they attend better when receiving information via these senses and are thus better able to interpret this information (BradleyJohnson, 1986).

The research findings for working memory (WM) are inconclusive, with most researchers finding no differences between blind and sighted people (Cornoldi \& Vecchi, 2000; Rokem \& Ahissar, 2009; Swanson \& Luxenberg, 2009)[7][8].

\section{METHODOLOGY}

\subsection{Sample}

This study investigated the relationship between working memory among students with visual impairment and normal sighted. Fifty students age range 10-16 years (Average I.Q) participated in the study, of whom 25 were visually impaired or blind living in Dehradun and 25 were normal sighted from Dehradun.

\subsection{Instruments}

The participant's working memory was assessed with different measures are as follows: 


\subsubsection{Digit Span Backward (subtest of the WISC III} intelligence test; Wechsler, 2005)[9]

Participants are dictated a series of digits, which they then have to repeat in reverse order. The sequences begin with two digits and increase one digit at a time, with two trials for each number of digits. Testing is terminated when the participant fails both trials for a particular number of digits. The number of sequences correctly repeated in reverse order is the child's raw score.

\subsubsection{Listening span task}

The experimenter reads a set of sentences aloud, asking the child to express a true/false judgment on the content of each sentence and to recall, at the end of the set, the last word of each sentence. Following the Daneman and Carpenter (1980)[2] procedure, the listening span score corresponds to the longest set of sentences of which the last words have been correctly recalled.

2.2.3 15 Words Test for Children (Kingma \& van der Burg, 1999)[10]

In this task, the experimenter reads 15 words aloud. There are no logical connections between the words. The respondent must then recall and repeat the words that they remember. This

procedure is repeated four times using the same words in the same order.

\section{PROCEDURE}

First of all, permission was taken from the chairperson of the school from the both group of participants. The data were collected individually. After the interaction with student's rapport was established with them.

All children were tested individually in a quiet room at their school. The total assessment took about $90 \mathrm{~min}$. The order of task administration was the same for all participants: 15 Digit Span Backwards, Listening Task and Making verbal/colour trails.

When both groups had completed their task, thanks were given to them.

\section{RESULTS}

The obtain score of visually impaired students (Mean=52.36, $\mathrm{SD}=7.926$ ) was compared to normal sighted students (Mean=48.00, SD=8.751), showed that difference between these two groups. In our study visually impaired students have been found to show superior performance in memory tasks to sighted students, because they have been shown on multiple occasions to compensate for their loss of sight by developing exceptional abilities in their remaining senses.

A possible reason for this is that parts of the brain that process visual information in sighted students are engaged in processing mnemonic (remembering) information in visually impaired students.

\section{DISCUSSION}

The present study showed performance of visually impaired students versus sighted students on various Working Memory tasks. The result showed that individual with visual impairments performed better than sighted individuals.

This finding is line with the results reported by Raz et al. (2007)[11] that visually impaired individuals have superior memory abilities because they have trained themselves serial strategies to compensate for the absence of visual information.

In this study, only verbal tasks were used to measure Working Memory, explicate the better performance of the visual impaired students relative to the sighted students. In the absence of vision in individuals, there is a considerable dependence on auditory-verbal information and the sequential processing of information may be particularly well- developed. According to Withagen, A., Kappers, A. L., Vervloed, M. J., Knoors, H., \& Verhoeven, L. (2013)[12], Working memories superior to those of the sighted students because of the brain's adaptation to a visual impairment. This superior ability is further thought to be the result of actual brain reorganization in blind people, whose brains become more adapted to spatial, sequential, and verbal information (Cornoldi \& Vecchi, 2000)[7].

Blind children may further benefit from the fact that verbal input is by definition sequential. In the absence of vision in individuals who are blind, there is a considerable dependence on auditory-verbal information and the sequential processing of information may be particularly well-developed. In addition to this, the main sensory channel for blind people to obtain information is touch. When blind individuals explore objects that cannot be held in two hands, they typically gather information about the object via successive exploratory movements (Hatwell, 2003; Re'vesz, 1950)[13][14].

Paivio and Okovita (1971) investigated paired-associate learning in the blind using high visual imagery (e.g. rainbow -shadow) and high auditory imagery (e.g. musicgong) word pairs. The found that the blind subjects recalled more high auditory imagery pairs than the sighted, 
while the reverse pattern held for the highly visualisable word pairs.

St Clair-Thompson (2010)[15] showed that in children digit span backward should be considered a measure of WM because in children - but not in adults - the central executive system is also involved in the performance of this type of task. More specifically, the transposition of order calls for the involvement of executive attentional control and processing of information. Ideally, in future studies, other types of WM tasks should be used but obviously in separate testing sessions in order to avoid fatigue.

When Smits and Mommers (1976)[17] compared blind versus sighted children on a digit span task, they found better performance for the blind. Hull and Mason (1995)[16] assessed a large group of blind children $(n=$ 314) using a digit span test that allowed comparison to the standardized WISC-R values obtained for sighted children. The blind children had - at best - light perception and performed significantly better than the sighted children. The group of late blind children with more than just light perception did not perform significantly better than the sighted children.

\section{CONCLUSION}

In a world where visually impaired are facing a lot of dogmas and prejudices, this study can be an eye opener and give people the insight. The studies show that in memory tasks, visually impaired performed better as compared to sighted people. The underlying reason for it was found to be the fact, that albeit their one sensory organ isn't as operational as the norms, they develop other senses as an compensatory mechanism, because of which they perform significantly better than sighted people.

\section{CONFLICT OF INTERESTS}

The author declared no conflicts of interests.

\section{ACKNOWLEDGEMENT}

The author appreciates all those who participated in the study and helped to facilitate the research process.

\section{REFERENCES}

[1] Swanson, H. L., \& Luxenberg, D. (2009). Short-term memory and working memory in children with blindness: Support for a domain general or domain specific system? Child Neuropsychology, 15, 280-294.
[2] Daneman, M., \& Carpenter, P. A. (1980). Individual differences in working memory and reading. Journal of Verbal Learning and Verbal Behaviour, 19, 450-466.

[3] Baddeley, A. D. (1986). Working memory. London: Oxford University Press.

[4] Baddeley, A. (2003a). Working memory: looking back and looking forward. Nature Reviews Neuroscience, 4, 829839.

[5] Baddeley, A. (2003b). Working memory and language: An overview. Journal of Communication Disorders, 36, 189208.

[6] Baddeley, A. D., \& Hitch, G. J. (1974). Working memory. In G. A. Bower (Ed.), The psychology of learning and motivation (pp. 47-89). New York: Academic Press.

[7] Cornoldi, C., \& Vecchi, T. (2000). Mental imagery in blind people: the role of passive and active visuo-spatial processes. In M. E. Heller (Ed.), Touch, representation and blindness (pp. 143-181). Oxford: Oxford University Press.

[8] Rokem, A., \& Ahissar, M. (2009). Interactions of cognitive and auditory abilities in congenitally blind individuals. Neuropsychologica, 47, 448-843.

[9] Wechsler, D. (2005). Wisc-III nl. Wechsler Intelligence Scale for Children Derde Editie Nederlandse Handleiding en Verantwoording. London: Harcourt Test Publishers.

[10] Kingma, K., \& van der Burg, W. (1999). Performance of 225 Dutch school children on Rey's Auditory Verbal Learning Test (AVLT): Parallel test-retest reliabilities with an interval of 3 months and normative data. Archives of Clinical Neuropsychology, 14, 545-559

[11] Raz, N., Striem, E., Pundak, G., Orlov, T., \& Zohary, E. (2007). Superior serial memory in the blind: A case of cognitive compensatory adjustment. Current Biology, 17,1129-1133.

[12] Withagen, A., Kappers, A. L., Vervloed, M. J., Knoors, H., \& Verhoeven, L. (2013). Short term memory and working memory in blind versus sighted children. Research In Developmental Disabilities, 34(7), 2161-2172.

[13] Hatwell, Y. (2003). Introduction: Touch and cognition. In Y. Hatwell, A. Streri, \& E. Gentaz (Eds.), Touching for knowing (pp. 1-14). Amsterdam: John Benjamins Publishing Company

[14] Re'vesz, G. (1950). Psychology and art of the blind. London: Longmans Green.

[15] St Clair-Thompson, H. (2010). Backwards digit recall: A measure of short-term memory or working memory? European Journal of Cognitive Psychology, 22, 286-296.

[16] Hull, T., \& Mason, H. (1995). Performance of blind children on digit-span tasks. Journal of Visual Impairment, 89, 166-169.

[17] Smits, B. W. G. M., \& Mommers, M. J. C. (1976). Differences between blind and sighted children on WISC verbal subtests. New Outlook for the Blind, 70, 240-246. 